\title{
ÉTICA Y RESPONSABILIDAD JURIDICA EN LAS ORGANIZACIONES EMPRESARIALES
}

\author{
Máximo Ugarte Vega Centeno (*) \\ E-mail: mugartev@unmsm.edu.pe
}

\begin{abstract}
RESUMEN
El cambio de siglo ha traído nuevas exigencias en la economía, la tecnología e incluso en el uso del Internet, las que han acentuado la divulgación de los conocimientos y el incremento del rol social de las empresas en el avance de las organizaciones, así como su creciente papel en las sociedades. Es allí donde surge la ética como responsabilidad en las organizaciones, en razón de la transparencia de las conductas empresariales que benefician a toda la comunidad y a la empresa misma, además de evitar las consecuencias jurídico-legales que conllevarían su no práctica.
\end{abstract}

Palabras clave: Etica, Responsabilidad Jurídica, Transparencia, Ventajas Competitivas

\begin{abstract}
The change of century has brought new demands in the economy, the technology and even, the use of the Internet, the ones that have accentuated the disclosure of the know-how and the increment of the social role of the businesses in the advance of the organizations, as well as its growing role in the societies. It is there where arises the ethics as responsibility in the organizations, with regard to the transparency of the business conducts that benefit all the community and to the same business, besides avoiding the juridical-legal consequences that would involve their not practical use.
\end{abstract}

Key words: Ethics, Legal Responsibility, Transparency, Competitive Advantages

(*) Doctor en Estudios Internacionales por la Universidad de Córdoba (España). Doctor Honoris Causa por la Universidad Tecnológica de los Andes de Apurímac. Magíster en Estudios Europeos por la Universidad Autónoma de Barcelona (España). Diplomado en Gestión por la Universidad Privada de Piura. Profesor Principal de la Universidad Nacional Mayor de San Marcos. 


\section{INTRODUCCIÓN}

El cambio de siglo ha traído nuevas exigencias en la economía, la tecnología e incluso en el uso de Internet las que han acentuado la divulgación de los conocimientos y el incremento del rol social de las empresas en el avance de las organizaciones, así como su creciente papel en ellas. Es allí donde surge la ética como responsabilidad en las organizaciones, en razón de la transparencia de las conductas empresariales que benefician a toda la comunidad y a la empresa misma, además de evitar las consecuencias jurídico-legales que conllevarían su no práctica.

En esa orientación podemos señalar que la actual coyuntura de esta realidad global o de globalización ${ }^{1}$ tiene como protagonista a la crisis financiera internacional ${ }^{2}$ que viene generando preocupación entre los agentes económicos y organizaciones empresariales debido a la interconexión de los mercados que reflejan cambios en los flujos financieros y comerciales, en la tecnología de la información y en las comunicaciones, en la movilidad de la mano de obra, en la interconectividad internacional y en las nuevas fuerzas de la competencia, que han acelerado la inminente recesión económica en todos los países, los que traerían como consecuencia el decrecimiento del PBI mundial al $4.5 \%$.

Estados Unidos y Europa pareciera que empiezan a despertar de su peor pesadilla económica: el desempleo en el país del norte en el año 2009 probablemente alcance un $6.1 \%$ con tendencia a subir por encima del $8 \%$; el rescate financiero presenta nuevos desafíos para los bancos ya que pareciera que no basta con la compra de las dos principales empresas de crédito hipotecario y la mayor aseguradora (American International Group - AIG) declaradas en quiebra por US\$ 85,000 millones, considerando además la pérdida de casi todo el capital del Citigroup, del Karma de Lehman Brothers, Fannie Mae, Freddie Mac y Bear Sterns y, en la industria automotriz, la debacle de General Motors, Ford y Chrysler.

Ante la actual situación internacional, el presidente de Estados Unidos, Barack Obama, reconoce que la culpa de la crisis económica la tienen los bancos por haber asumido riesgos "exorbitantes" con la compra de títulos de calidad dudosa con el dinero de otros ${ }^{3}$. En ese sentido se planteó el rescate de los bancos y de los banqueros irresponsables por parte del gobierno con dinero de los contribuyentes, mediante la inyección de US\$ 750,000 millones para comprar acciones preferentes en los bancos. Para evitar que continúe el desastre, el gobierno de Estados Unidos decidió invertir otros US\$ 20,000 millones, más los US\$ 25,000 millones que aportó como parte del megasalvataje, adicionales a los US\$ 326,000 millones utilizados para garantizar operaciones colaterales del Citigroup, y últimamente, un nuevo salvavidas económico inyectando US\$ 787,000 millones a la decaída economía, pensando que este paquete marque el principio del fin de la crisis internacional.

Lo expuesto nos lleva a repensar el rol del estado y del sector financiero, donde el gobierno también tiene el derecho de comprar acciones comunes a las empresas financieras en quiebra o de ser inversionista pasivo en las instituciones que reciban capital gubernamental. En otras palabras, se estarían estatizando las economías privadas.

Como bien sabemos, en las relaciones empresariales -y particularmente en la realización de negocios- la omisión de información o la desinformación a terceros puede llevar a que una organización se beneficie lucrativamente, pero también a que si se descubre la omisión o falsedad ésta sea sancionada económica y jurídicamente. Ante estas conductas es cuando se plantea la reflexión de la ética.

\section{HIPÓTESIS}

La inclusión de la ética en las organizaciones evitaría las responsabilidades jurídicas y generaría ventajas competitivas; además, su incorporación al interior de las empresas debería convertirse en una estrategia organizacional.

\section{ANÁLISIS Y DISCUSIÓN}

Por las características del estudio descriptivo tomaremos en consideración los siguientes indicadores de la hipótesis planteada:

1 Véase sobre globalización. Aznarán Castillo, Guillermo. (2003). Págs. 77-82.

2 Para comprender mejor como funciona el sistema financiero internacional se recomienda leer a Francois Chesnais, Francois Morin, al egipcio Samir Amin, Immanuel Wallerstein, André Gunther y a Adam Smith.

3 Ver diario Expreso, Lima, 10 de febrero del 2009. 
- La inclusión de la ética en las organizaciones.

- La inclusión de la ética en las organizaciones evitaría las responsabilidades jurídicas.

- La ética como ventaja competitiva.

- La incorporación estratégica organizacional.

\section{La inclusión de la ética en las organizaciones} jurídicas. Podemos encontrar los primeros antecedentes de responsabilidad de la empresa ante las leyes de un Estado y sujeta a derechos y deberes de igual forma que las personas naturales, en la sentencia del Tribunal Supremo de Estados Unidos del caso Dartmouth Collage versus Woodward de 1819, donde se reconoce que la empresa tiene personalidad jurídica; es decir, que podía realizar operaciones, contratos de personal, adquirir bienes, etc. Décadas después, en 1909, el mismo Tribunal dicta la Resolución de Nueva York Central Railroad versus Estados Unidos, sobre la responsabilidad jurídica por los hechos que hubieren generado los trabajadores; en otras palabras, se indicaba que había responsabilidad corporativa al margen de la responsabilidad penal personal de los trabajadores.

A partir de 1970 surge la incorporación de la ética empresarial como responsabilidad social corporativa; desde luego que no fue un camino fácil por las reticencias de los empresarios a extender el ámbito de responsabilidades normativo-legal al ámbito ético-social como lo demuestran los juicios en los tribunales, donde las empresas terminaron por aceptar sus responsabilidades y el pago de las indemnizaciones respectivas en las diferentes sentencias judiciales.

Las empresas se resistían a que se pasara de una responsabilidad penal de carácter legal a una de responsabilidad social-ética argumentando que las empresas ni tenían cuerpos a encarcelar ni almas que condenar y que la sociedad no les podía imponer actos filantró- picos. Además, el dinero que ganaban era de su propiedad y podían hacer lo que quisieran siempre y cuando no hicieran daño a terceros. En los años 80 se difunden masivamente denuncias de comportamientos nada éticos en las empresas como acoso sexual, fraude fiscal, publicidad engañosa, etc., para sensibilizar a la sociedad contra estas prácticas anti-éticas.

La segunda "incorporación" de la ética empresarial se da en el contexto de los años 90 con la ratificación del Congreso de Estados Unidos en relación a los Federal Corporate Sentencing Guidelines. Con esta ley quedaba en evidencia el riesgo que corrían las empresas que no incorporaban la ética en sus diferentes operaciones, debido a las sanciones económicas que los Tribunales podrían imponerles por sus infracciones y delitos en este ámbito.

Podemos apreciar que existe un proceso de evolución de una responsabilidad social ${ }^{4}$ corporativa a una autorregulación, proceso que ha empezado a surtir efecto y que ya aparece en las legislaciones de Estados Unidos y de la Unión Europea ${ }^{5}$, lo que ha contribuido al impulso, institucionalización y colección metódica de los principios de la ética. Es de precisar que en tiempos en los que destacan los conceptos de competitividad, calidad, participación y globalización, la ética ocupa un lugar determinante para el desarrollo de los países ocupados en lograr mayor productividad y una mejora de la calidad de vida de sus ciudadanos.

En cambio, a inicios del tercer milenio, nos encontramos en medio de una crisis financiera internacional que está generando desestabilización en toda esta aldea global como consecuencia de la crisis del sistema hipotecario de Estados Unidos y de la crisis crediticia de los bancos, lo que ha generando desconfianza entre los mismos bancos norteamericanos y europeos y ha hecho que dejen de prestarse dinero afectando la liquidez del sistema y, como consecuencia, que se restrinjan los créditos a las empresas.

4 Véase sobre Responsabilidad Social: Robbins, Stephen y Mary Coulter. (2000). Págs.140-179.

5 Ver la Foreign Corrupt Practices en la que se declara ilegal el pago y la oferta de pago en dinero o especie, directa o indirectamente, a funcionarios representantes electos para influir o conseguir una venta o un contrato para una empresa norteamericana. Véase también las leyes anti corrupción de actos, extorsiones y sobornos en general, con relación a los gobiernos locales, estatales y federales de los Estados Unidos en Anti-Kicbak, Act of 1986, Byrd Amendment, Federal Election Campaign Act, entre otros. 
Podemos decir que esta crisis es producto de la codicia, del deseo de obtener dinero fácil. Esa actitud de ganar dinero fácil conlleva a la euforia de precios y préstamos, generándose una crisis mundial que nació en Estados Unidos y que ahora afecta a todos los países.

En la era de la globalización ningún país puede estar al margen de los efectos negativos de la inestabilidad internacional. El Perú ya siente las consecuencias de la crisis internacional: la minería y el sector textil están con dificultades y la tasa de interés ha subido, teniendo repercusiones en menor empleo en minería y agroindustria. En la microempresa las tasas de interés anual sobrepasan el $35 \%$, un sobrecosto que afectará la competitividad exportable y subirá los precios internos.

Además, es importante señalar que la crisis financiera y bursátil trae como consecuencia que se deprecien las materias primas, excepto el oro, y que los mercados de los países en desarrollo se restrinjan y presenten riesgos en dos grandes categorías: riesgo comercial (en el ámbito de los negocios donde opera una empresa) y riesgo financiero (posibilidad de que cambios adversos en las condiciones financieras del futuro pueden afectar los ingresos o los costos) ${ }^{6}$, ya que se compran menos exportaciones de los sectores de minería, agricultura y textiles; en otras palabras, las ventas se reducen en volumen y dinero. Asimismo, ya se está exigiendo una reorientación del sistema financiero internacional, donde la hegemonía difícilmente podrá seguir en manos de Estados Unidos, y se prevee que los centros hegemónicos van a orientarse hacia los países emergentes como China, Brasil, Rusia e India que serán los más importantes en los próximos veinte años; es decir, terminó la bipolaridad y con ella su sistema de regulación y de seguridad internacional y se iniciaría la globalización multipolar, como muchos autores la denominan, además de generarse el momento propicio para que los bloques regionales o integraciones económicas, comerciales y financieras en los diferentes mercados (África, Asia, América
Latina, El Caribe y Medio Oriente) puedan regular colectivamente la reestructuración global de la economía mundial ${ }^{7}$.

2. La inclusión de la ética en las organizaciones evitaría las responsabilidades jurídicas. La ética y la responsabilidad jurídica en las organizaciones empresariales vienen generando posiciones distintas ${ }^{8}$. Una de estas posiciones está vinculada con la idea de que es imposible unir los negocios con los valores; es decir, un negocio bueno en el sentido moral es un mal negocio en el sentido económico. Estas nociones son inducidas por conceptos como competitividad, búsqueda del lucro, éxito profesional o la cultura de resultados inmediatos generada por la falta de comunicación, transparencia, decisiones o estilos gerenciales, en este caso en el ámbito financiero internacional. Otra posición señala que sería un error tener una visión o enfoque solamente de beneficio o de sacar una ventaja puramente económica, olvidando que los negocios se realizan a través de personas que vienen a ser las responsables de su desarrollo.

En ese sentido, al comentar sobre la ética, necesariamente tenemos que recurrir a la filosofía para poder entender mejor los orígenes de la palabra "ética" que viene del griego éthos. Aristóteles se refería a éthos como temperamento, carácter, hábito, modo de ser; en cambio, otros autores se referían a su significado como suelo firme, fundamento en la praxis, raíz de donde brotan todos los actos, o que viene del concepto de la morada o lugar donde se habita referido al hombre o los pueblos.

La ética puede ser definida también como el estudio de lo moral, que trata de regular la actividad humana en razón del bien, y se caracteriza por ser reflexiva porque estudia los actos no como son sino como deberían ser, y es práctica por estar orientada a la acción humana. Otros autores, en cambio, la explican como reglas y principios que definen una conducta correcta o incorrecta ${ }^{9}$.

6 Cavani Grau, Carlos y Freyre Valladolid, Mayela. (2003). Págs. 43-51. Asimismo, es importante señalar que existen firmas auditoras y calificadoras de riesgo; entre las principales tenemos a Price Waterhouse, Ernest \&Young, Delloitte, KPMG, Standard \& Poors, Moody's, etc.

7 Harris, Richard L. (2008).

8 Begazo, José Domingo. (2003). Págs. 43-51.

9 Robbins, Stephen y Coulter, Mary. (2000). Págs. 159 y ss. 
Para comprender mejor la responsabilidad jurídica en las organizaciones empresariales es necesario hacer algunas diferencias entre moral, valor, ética y el código de ética ${ }^{10}$. La moral se refiere a las costumbres, los actos y los pensamientos humanos, en especial desde el punto de vista de su bondad o malicia ${ }^{11}$. El valor son las convicciones básicas acerca del bien o del mal; otros señalan que es la cualidad o conjunto de cualidades que hacen que una persona o cosa sea apreciada ${ }^{12}$. El valor no lo poseen los objetos por sí mismos, sino que éstos lo adquieren gracias a su relación económica social; en cambio, lo ético trata de la valoración moral de los actos humanos o el conjunto de principios y normas morales que regulan las actividades humanas ${ }^{13}$. Cuando nos referimos al código de ética lo entendemos como la declaración formal de los valores fundamentales de una organización y las normas éticas que ésta espera que sus trabajadores sigan. Y, cuando hablamos de empresa, la definimos como una sociedad mercantil de producción de bienes y servicios.

La incorporación de la ética en las organizaciones, por su carácter multidisciplinario, ayudaría a solucionar en parte los problemas de responsabilidad ya que la ética, en sus aspectos filosóficos y como ciencia, tiene relación con todas las disciplinas y con algunas mucho más como describimos a continuación en términos generales:

- Ética y Sociología. La Sociología estudia el comportamiento del hombre en forma global, es una ciencia que estudia hechos, mientras que la Ética es una ciencia de derechos.

- Ética y Derecho ${ }^{14}$. El Derecho es el conjunto de normas que rigen la conducta humana, mientras que la Ética difiere del Derecho por ser normas propias de cada persona natural o jurídica. De acuerdo con diferentes autores podemos indicar algunas diferencias principales: las normas éticas son autónomas (cada individuo debe darse sus propias normas), se rigen por aspectos internos, son unilaterales (el cumplir una norma no implica el surgimiento de un derecho o una obligación por parte de otras personas), y son incoercibles (aún cuando llevan un carácter obligatorio, generalmente no conlleva un castigo explícito en el caso de no cumplirlas). En cambio las normas de derecho son heterónomas (provienen de una autoridad diferente al individuo), se rigen por aspectos externos, son bilaterales (una obligación implica un derecho y viceversa) y son coercibles (la autoridad que ha establecido ciertas normas civiles tiene la facultad de exigir el cumplimiento de ellas, y para llevar a cabo dicha tarea impone vigilancia, fiscalización, sanciones, entre otras).

- Ética y Economía. La Economía es la ciencia que trata de la producción, distribución y consumo de bienes materiales (el trabajo, la mercancía, el dinero, la ganancia, la utilización del trabajo, el comercio, entre otros). La Ética se relaciona con esta ciencia en el aspecto de la vida del ser humano (subsistencia, problemas pecuniarios, su lucha por el alimento, vivienda, ropa); en resumen está relacionada con la injusticia de los sueldos y salarios, la responsabilidad de los empleados, la colonización del trabajo, entre otros.

Ahora bien, para el desarrollo de toda organización es importante el factor humano que dirige

10 Por eso afirmamos que todas las personas tenemos ideas sobre lo que está bien y lo que está mal, sobre lo justo y lo injusto. Cuando estas ideas surgen internamente y creemos en ellas a conciencia, entonces forman parte de ese enigmático y a la vez maravilloso mundo que constituye la moral. La ética es la rama de la filosofia que ha sentido fascinación por el mundo de la moral y ha reflexionado sobre las razones de unos y otros, intentando descubrir qué argumentos son más sólidos y en qué radica esa solidez; en ese sentido, como indica Javier Iguiñiz, el hombre de acción de nuestra época - sea el político, el empresario o funcionario público- evalúa a través de sus consecuencias, mientras que la ética del hombre religioso se aferra a valores que él considera absolutos.

11 Editorial Planeta. (2001). Pág. 943.

12 Ibid, pág. 1461.

13 Ibid. pág. 590.

14 Al respecto véase, Calamandrei, Piero. (1983). Cuadros Villena, Carlos. (1994). Cueto Rúa, Julio. (2000). Págs. 76 y ss. 
e integra estas empresas, ya que son las personas las que conducen a las organizaciones a desarrollarse, y por las acciones que realicen, ya sean correctas o incorrectas, se determinará el beneficio o perjuicio desde el punto de vista ético-empresarial. En ese sentido sería un error tener una visión solamente economicista, olvidando que los negocios se realizan a través de personas que vienen a ser las responsables de las actividades de la empresa. Por eso, estando de acuerdo con otros autores, señalamos que una buena actitud ética es una buena actitud profesional; por lo tanto una buena actitud ética es una buena actitud profesional frente a la sociedad junto a la honradez, veracidad y honestidad ${ }^{15}$, por lo que su inclusión en las organizaciones jurídicas es una necesidad si es que éstas tienen una visión a corto, mediano o largo plazo; lo contrario significaría estar más lejos de la realidad.

2.1La ética y la normatividad jurídica de la empresa en el ámbito nacional. Entendemos que la composición de la empresa ${ }^{16}$ no sólo incorpora a empresarios, trabajadores y comunidad, sino también normas y valores, lo que ha generado diferentes definiciones de empresa que la mayoría de los ordenamientos jurídicos del derecho comparado ha evitado precisar o definir.

En nuestra normatividad jurídica no se ha conceptualizado a la empresa por estar enfocada desde el punto de vista comercial que giró en torno al comerciante. En el proyecto de Ley Marco del Empresariado recién podemos encontrar una definición: "organización económica dedicada a la producción o comercialización de bienes o a la prestación de servicios". De esta definición se puede observar que existen dos enfoques: el estático y el dinámico. El primero toma en consideración todos los elementos aislados de la empresa como maquinaria, capital, trabajadores, materia prima, inmuebles, sin ninguna interrelación; en cambio, el enfoque dinámico, si bien observa los mismos elementos que el supuesto anterior, los vincula con el destino económico único y está referido a una idea organizadora:

"la empresa es un círculo de actividades dirigidas por la idea de la organización; es, al mismo tiempo, presupuesto racional de trabajo de la empresa y el resultado de ese mismo trabajo"17.

De otro lado, la aparición de la empresa en el escenario jurídico configura literalmente un evento extraordinario y sorprendente, que exigía aceleradamente una respuesta que se da con el surgimiento del Derecho Empresarial; sin embargo, este nuevo derecho creó muchos debates y desacuerdos entre los especialistas de Derecho Comercial y Mercantil. El principal problema que afronta está en relación con su autonomía; para ello debemos tener en consideración que este derecho gira en torno a la empresa: su actuación se circunscribe al conjunto de normas jurídicas relativas a los empresarios y a los actos que surgen en el ejercicio de su actividad económica.

El Derecho Empresarial presenta un contenido multidisciplinario por tratarse del estudio de una institución tan compleja como es la empresa, que abarca los aspectos administrativo, civil, laboral, mercantil, tributario, concursal, entre otros, y muchas veces incurre u omite en actos ilícitos como los delitos societarios, laborales, delito de quiebra, contra la propiedad intelectual, contra el orden económico, contra el consumidor, represión a la competencia desleal y delitos financieros (que son los más frecuentes); actos generados por la complejidad de su actividad que produce un conjunto de conductas que buscan beneficiarse a expensas de los demás, afectando a la actividad económica y a la planificación estatal de la economía, buscando pasar por alto las normas estatales que organizan y protegen la vida económica, por lo que la delimitación de estos delitos es trascendental ${ }^{18}$. Consecuentemente, la pregunta es dónde se encuentra regulado lo ético.

15 Polo Santillán, Miguel Angel. (2003). Vuelva, Julio. (2002).

16 Anzola Rojas, Sérvulo y otros. (2000). Págs. 11-55.

17 De la Puente y Lavalle, Manuel. (1997). Págs. 13-14.

18 Ugarte Vega-Centeno, Máximo. (2003). Págs. 35-39. Torres y Torres Lara, Carlos. (1985). Págs. 1-62. Mena Ramírez, Miguel. (1986). Pág. 237. 
En términos generales, podemos afirmar que existen normas reguladoras de la conducta humana que a través del tiempo demuestran que el hombre es esencialmente social: nace perteneciendo a una familia para luego integrarse a un colegio, un centro de trabajo, un pueblo o una nación; por lo tanto, el hombre ya no puede actuar arbitrariamente ya que la propia vida social está regida por normas reguladoras de la conducta humana, entre las que podemos citar a las normas técnicas y las éticas. Las normas técnicas se refieren a las reglas y principios que tiene toda actividad de trabajo, servicio, asesoramiento, entre otros; en cambio las normas éticas regulan la conducta humana frente a los demás y pueden ser normas religiosas, morales, de sociabilidad y normas jurídicas. En otras palabras, toda sociedad requiere de normas jurídicas que emana y precisa el derecho, como las que obligan a realizar determinados actos o contrariamente impone prohibiciones. En ese sentido, como bien sabemos, la ética es el código de principios morales que modela el comportamiento de una persona, grupo u organización con respecto a lo que es correcto o incorrecto. Los valores éticos establecen normas en cuanto a lo que es bueno o malo en la conducta y en la toma de decisiones.

La ética es diferente de los comportamientos regulados por ley. Las leyes gubernamentales surgen de un conjunto de principios y regulaciones codificadas que describen la forma cómo la gente ha de actuar; generalmente son aceptadas en la sociedad y se pueden hacer cumplir mediante el Poder Judicial (jueces, tribunales, etc.). En cambio las normas éticas, en su mayor parte, se aplican a una conducta que no está prevista por la ley; además la ley gubernamental cubre comportamientos que no necesariamente abarcan las normas éticas.

Con frecuencia las leyes actuales reflejan juicios morales combinados, pero no todos los juicios están codificados en leyes. En ese sentido, existen muchas conductas que no se han codificado en nuestro sistema jurídico y los responsables de las organizaciones deben ser sensibles a las normas y valores emergentes de su entorno interno e externo. En lo interno, es decir la ética en el derecho peruano, podemos encontrar con mayor nitidez su regulación ética dentro del Derecho Administrativo que ha recogido en una sola norma aspectos de orden moral y ético a la que se ha denominado Ley del Código de la Función Pública, la que rige en el ámbito estatal de los servidores públicos y que se encuentra en concordancia con la Ley de Procedimiento Administrativo General (Ley № 27444), contexto en el cual se incluye al Poder Ejecutivo, Judicial, Legislativo, Gobiernos Regionales, Locales (que involucran a las Municipalidades Distritales y Provinciales), organismos a los que la Constitución Política y las leyes confieren autonomía; así como las demás instituciones, organismos, proyectos y programas del Estado cuyas actividades realizan en la administración pública, así como las personas jurídicas bajo el régimen privado que prestan servicios públicos ${ }^{19}$.

También podemos encontrar para las empresas $^{20}$ que la responsabilidad social viene a ser una extensión de esta idea cuando se refiere a la obligación de los gerentes de tomar decisiones y emprender acciones para que la organización contribuya al bienestar e intereses de la sociedad y de ella misma ${ }^{21}$.

3. La ética como ventaja competitiva. Lo ético comprende la intención de las organizaciones de actuar con transparencia en sus relaciones empresariales; como dice Rinnov Kan, sin valores sólidos estamos coqueteando con el desastre. Con valores sólidos podemos enfrentar a los mercados internacionales; en otras palabras, con la ética corporativa se pueden lograr ventajas competitivas tales como atraer clientes y personal calificado, y se pueden desterrar prácticas corruptas que perjudican el valor y la economía de un país.

19 Frisancho Aparicio, Manuel y Peña Cabrera, Raúl. (2003). Pág. 256. Abanto Vásquez, Manuel. (2001). Págs. 21-191. www. proetica.org.pe.

20 Valenzuela, Luis Fernando. (2005). Pág. 397. Jonas, Hans. (1995). Pág. 398.

21 Sobre responsabilidad social y desempeño económico ver Robbins, Stephen y Coulter, Mary. Op.cit. Págs. 151 a 154 . De los mismo autores, sobre ética gerencial, págs. 158 a 183. 
En ese sentido, coincidiendo con muchos autores, para desarrollar el valor ético en la empresa debemos empezar a diferenciar cuatro fases que describen el contenido de cómo se construye una empresa: la creación, la diferenciación, la unificación y la congregación. La primera fase se refiere a una o varias personas que emprenden una actividad lucrativa. La segunda, se refiere a la diferenciación que se da principalmente en dos aspectos sustanciales, tales como la titularidad y el patrimonio (titularidad se entiende como disimilitud entre persona jurídica, titular de empresa y el empresario, y en relación al patrimonio es distinguible el perteneciente a la persona jurídica que corresponde al empresario que se expresa en lo que conocemos como sociedad anónima). La tercera fase, conocida como unificación, se refiere al patrimonio de la persona jurídica y se concibe como la sumatoria de elementos aislados como máquinas, dinero y materia prima; posteriormente se unen las marcas, acciones, derechos, tecnología, patentes, canales de distribución, y la conjunción de todo ello con la actividad que desarrolla es conocido como empresa; entonces podemos decir que este es el momento más importante de la evolución de la empresa.

Como última fase tenemos la congregación, es decir, cuando la empresa extiende sus alcances a diferentes grupos de la sociedad. Es en ese momento en el que nace la congregación, ya que con el desarrollo de la comunicación y la tecnología se canalizan en la empresa recursos que pueden ser proporcionados por un número reducido de titulares, donde conviven inversionistas, trabajadores, consumidores y usuarios, acreedores y el Estado.

$\mathrm{Si}$ incorporamos a estas cuatro fases arriba mencionadas los valores éticos, se generarían valores agregados que harían que las empresas sean mas competitivas y además mejorarían conductas y valor, claro está, siempre y cuando se incorporen a la organización valores básicos como la igualdad, libertad, diálogo, respeto y solidaridad $^{22}$.
Si se logran estos valores se puede llegar a generar mayor valor económico; por lo tanto, la ética ayuda a mejorar la organización y el funcionamiento de la empresa mediante varias vías. Como indica Carlos López ${ }^{23}$, la ética reduce los conflictos de los miembros que forman la empresa, mejora la imagen exterior de sí misma, y supone un componente esencial del concepto de "calidad total", tan importante en estos días.

4. La incorporación estratégica organizacional. Como bien sabemos, toda organización que realiza cualquier tipo de negocios necesariamente tendrá que optar por una estrategia a nivel corporativo que abarque todas sus actividades, y la incorporación estratégica de la ética en una organización mejoraría sus ventajas competitivas (entendida como la utilización de alguna estrategia para ser más competitivos que las demás empresas que compiten en el área), o disminuirían si se practican formas de conducta como mentir, fingir, disimular, hacer trampas ("hecha la ley, hecha la trampa") que anteriormente se veían reprochables y que hoy se han convertido para muchas organizaciones en conductas nada reprochables, lo que deviene en preocupación por la no aplicación y práctica de las normas éticas.

Como hemos visto anteriormente, las exigencias del mercado cada vez son mayores y la ética, en su concepto tradicional, ha ido evolucionando y cada vez es más difícil emitir un juicio apropiado sobre cómo podemos atribuir una conciencia corporativa empresarial.

En ese sentido, se reafirma una vez más el enfoque de la administración basado en valores compartidos con la organización que son establecidos, promovidos y practicados por los gerentes; dichos valores reflejan lo que la organización representa y las creencias de la misma, por eso los valores compartidos constituyen la cultura de la organización e influyen tanto en la forma en que ésta funciona como en el comportamiento de los empleados ${ }^{24}$.

22 López, Carlos. En http//www.gestiopolis.com/canales/ gerenciales, pág. 2.

23 Ibid. págs. 2-3.

24 Robbins, Stephen y Coulter, Mary. Op.Cit, pág. 149. Véase también Chatman, J. y Caldwell. (1991). Págs. 487-516. 
Sin embargo, la incorporación de valores en los recursos humanos como estrategia para cambiar la forma de pensar, el trabajo en equipo y la comunicación, la cultura de la confianza $y$, en general, una cultura empresarial, contribuirían a generar un ambiente adecuado y más humano dentro de la empresa, que reemplazaría a la práctica coercitiva-burocrática que muchas veces ha sido lo más común. La ética, por lo tanto, tiene influencia en las relaciones empresariales y, como consecuencia, en los resultados.

La aplicación de instrumentos de valoración de gestión ética que pudieran ayudar a demostrar quiénes realmente están implicados con los valores de la organización, es una opción que ayudaría a determinar la gestión de la empresa con responsabilidad y transparencia. Sin embargo, la práctica de qué es el criterio de la verdad demostrará si las actitudes son buenas o malas en la empresa y se premiarán o sancionarán las mismas,

Por último, podemos señalar que en el Perú tenemos que seguir reforzando los grandes valores, valores que muchas veces nos asustan, nos conmueven, nos sacuden y que tienen que seguir afrontándose en distintos ámbitos: en lo moral (derechos humanos), en lo político (respeto al estado de derecho y sus instituciones), en lo social (la pobreza) y en lo jurídico (la lucha contra el crimen organizado en sus diferentes expresiones); en este caso la criminalidad económica con decisiones sustantivas y orgánicas dentro del sistema de administración de justicia penal.

\section{CONCLUSIONES}

1. La globalización nos ha traído nuevos retos y exigencias en las relaciones económicas y empresariales, donde la ética toma más relevancia y cada vez se hace más exigente.

2. Para que la ética no quede en palabras o dichos es importante incluirla o institucionalizarla mediante normas y actitudes de honestidad para así evitar los riesgos jurídicos-legales.

3. La ética empresarial no es un valor añadido sino un valor intrínseco de las organizaciones, por eso el fortalecimiento de los valores y principios de las mismas tiene efectos en el capital humano. Es importante generar como ventaja competitiva una cultura de responsabilidad y principios éticos como la transparencia que viene a ser un valor intangible de toda organización por lo que se procura que la empresa, frente a la sociedad, tenga un comportamiento honrado, veraz y honesto.

4. La actitud transparente de las personas que integran una organización se exteriorizará en las actividades que realicen dentro y fuera de ella.

5. Si la ética se incorporase como una exigencia estratégica en toda empresa, se evitarían los riesgos jurídicos-legales en que pudiera incurrir la organización si no actuara bajo sus principios.

6. La ética empresarial, entendida como comportamientos basados en los valores, beneficia a toda la sociedad, a la empresa misma y evita riesgos jurídico-legales, por eso es importante que los valores de la visión y misión de toda organización deben ser compartidos y puestos en la práctica. En consecuencia, si las personas jurídicas son autónomamente responsables por sus actos, sus conductas deben de realizarse de acuerdo con los valores que predican.

7. Hoy podemos afirmar que la economía y las finanzas internacionales están debilitadas como consecuencia de la codicia e irresponsabilidad de algunas organizaciones bancarias.

8. Y, por último, podemos decir que seguirá siempre en agenda el conflicto no resuelto entre la ética, lo jurídico y los beneficios económicos.

\section{BIBLIOGRAFÍA}

Abanto Vásquez, Manuel. (2001). Los Delitos contra la Administración Pública, Lima, Editorial Peisa.

Anzola Rojas, Sérvulo y otros. (2000). Curso básico de administración de empresas. Colombia, Editorial Mc Graw Hill.

Aznarán Castillo, Guillermo. (2003). "Respondiendo preguntas sobre la globalización". En: Gestión en el Tercer Milenio, Revista de Investigación de la Facultad de Ciencias Administrativas de la Universidad Nacional Mayor de San Marcos. Lima, UNMSM, № 10, enero del 2003.

Begazo, José Domingo. (2003). "El Estado, los empresarios y la ética empresarial". En Gestión 
en el Tercer Milenio, Revista de Investigación de la Facultad de Ciencias Administrativas de la Universidad Nacional Mayor de San Marcos. Lima, UNMSM, № 10, enero del 2003.

Calamandrei, Piero. (1983). De las buenas relaciones entre los jueces y abogados en el nuevo proceso civil. Buenos aires, Editorial Desalma.

Cavani Grau, Carlos y Freyre Valladolid, Mayela. (2003). "A propósito del riesgo-país"; en Gestión en el Tercer Milenio. Revista de Investigación de la Facultad de Ciencias Administrativas de la Universidad Nacional Mayor de San Marcos. Lima, UNMSM, № 10, enero del 2003.

Cuadros Villana, Carlos. (1994). Ética en la abogacía y deontología forense.

Cueto Rua, Julio. (2000). Una visión realista del derecho. Los jueces y los abogados. Buenos Aires, Editorial Abeledo Perrot.

Chatman, J. y Caldwell. (1991). "People and organizational culture. A profile comparison approach assessing Person". Organization Fit. En Academy Of Management Journal. Nueva York, Mc Graw Hill, september 1991.

De la Puente y Lavalle, Manuel. (1997). "Contenido de Derecho Mercantil Moderno". En Revista de Estudios Privados. Lima, Facultad de Derecho de la Universidad de San Martín de Porres. Lima, UPSMP, Año 2, № 2.

Diario Expreso. (2009). Lima, 10 de febrero del 2009.

Editorial Planeta. (2001). Diccionario básico de la lengua española. Barcelona, Editorial Planeta.

Frisancho Aparicio, Manuel y Peña Cabrera, Raúl. (2003). Delitos contra la administración de justicia. Lima.

Harris, Richard L. (2008). "Alternativas latinoamericanas frente a la globalización y el capitalismo". En Nueva Sociedad. Mexico, № 214, marzo - abril de 2008.
Jonas, Hans. (1995). El principio de responsabilidad. Barcelona, Editorial Herder.

Mena Ramírez, Miguel. (1986). La empresa en el Perú. Lima, Editorial Cuzco.

Polo Santillán, Miguel Angel. (2003). "Ética profesional”. En Revista Gestión en el Tercer Milenio. Lima, Facultad de Ciencias Administrativas de la UNMSM. Lima, UNMSM, Año 6, $\mathrm{N}^{\circ} 12$, diciembre 2003.

Robbins, Stephen y Coulter, Mary. (2000). Administración. Sexta Edición en español. México, Editorial Prentice-Hall Hispanoamericana SA.

Torres y Torres Lara, Carlos. (1985). "Persona y Empresa”. En Revista Peruana de Derecho de la Empresa - Separata Doctrinaria. Lima, Editorial Asesorandina.

Ugarte Vega-Centeno, Máximo. (2003). "El Derecho penal económico como alternativa en la solución de los llamados Delitos Económicos Empresariales". En Revista Gestión en el Tercer Milenio. Lima, Facultad de Ciencias Administrativas de la UNMSM. Lima, UNMSM, Año 6, № 12, diciembre 2003.

Valenzuela, Luis Fernando. (2005). Perspectivas de la responsabilidad social empresarial. Colombia, Editorial Manizales: Gráficas Jes.

Vuelva, Julio. (2002). Ética profesional de enfermería. Bilbao, Desciré de Brouwer.

\section{INTERNET}

López, Carlos. "La ética empresarial como fuente de ventaja competitiva". En http//www.gestiopolis.com/canales/gerenciales.

Proética. Consejo Nacional para la Ética Pública. En www.proetica.org.pe. 